\title{
Science underpinning the safety case of deep geological repositories - challenges in the past and in the future and how to maintain knowledge and competence during operation
}

\author{
Johan Andersson* \\ Unit of Nuclear Fuel Repository, Swedish Nuclear Fuel and Waste Management Co. SKB, Box 3091, 16903 Solna, Sweden
}

Received: 12 March 2019 / Accepted: 18 September 2019

\begin{abstract}
Final repositories for spent nuclear fuel are approaching implementation. A prerequisite for these advancements is that it has been shown that the repository can be constructed and operated in practice in such a way that safety can be assured both during operation and over very long time scales. The success rests on decades of structured and objective-driven research and development. A key element of the research strategy has been to ensure adequate in-house competence and expertise. Also, openness and international cooperation are essential. Workable procedures for data qualification, version control as well as internal and external peer review have gained importance. When the programmes now enter a new phase of construction and operation new challenges will arise. Even if the implementing organisations would need to keep a core competence on post closure safety assessment international cooperation will be even more important on developing, sharing and managing the knowledge needed.
\end{abstract}

\section{Introduction}

Final repositories for spent nuclear fuel are approaching implementation. In 2011, SKB applied for a permit to build a KBS-3 type final repository for spent nuclear fuel at the Forsmark site. The application has now been examined by the Swedish Radiation Safety Authority (SSM) under the Act on Nuclear Activities and by a Swedish Land and Environmental Court under the Environmental Code. On January 23 2018, SSM and the Court both issued their statements to the Swedish Government. SSM recommends the Government to grant permission for a final repository at the Forsmark site. It also points to issues that SKB needs to resolve in coming phases of the step-wise licensing process under the Act on Nuclear Activities. The Land and Environmental Court approved in its statement parts relating to the choice of Forsmark as the site for the repository, post-closure aspects related to the rock and the buffer and the environmental impact assessment. It also considered that supplementary information regarding five issues related to the long-term integrity of the copper canisters be presented and evaluated before permission is considered. In March 2019 SKB submitted supplementary material, as requested by the Government, demonstrating that these issues do not jeopardize the post-closure safety of

\footnotetext{
* e-mail: johan.andersson@skb.se
}

a KBS-3 repository at the Forsmark site. The matter now rests with the Government. Construction of the repository may start around 2023 and operation may start early 2030 , provided the Government grants a decision during 2020. In Finland, a KBS-3 type repository for the spent fuel has obtained a construction license in 2015. Provided licenses are approved operation may start around 2024.

An application to expand the repository for low-level operational waste was submitted in 2014. In January 2019, SSM recommended approval of license in its statement to the Land and Environment Court. The main hearing in Environmental Court will take place in late September 2019, statements to the Government may follow late 2019 and a government decision may be at hand during 2021 . Regarding the long-lived intermediate level wastes a safety assessment of a conceptual repository design will be presented during 2019. This will form the basis for further development of the engineered barriers, waste acceptance criteria, and the siting process.

A prerequisite for these advancements is that it has been shown that the repository can be constructed and operated in practice in such a way that safety can be assured both during operation and over very long time scales. The success of the programmes rests on decades of structured and objective-driven research and development, including both theoretical assessments and practical test in the laboratory and in full scale. This has been possible by a dedication to bring the repository programme to a 


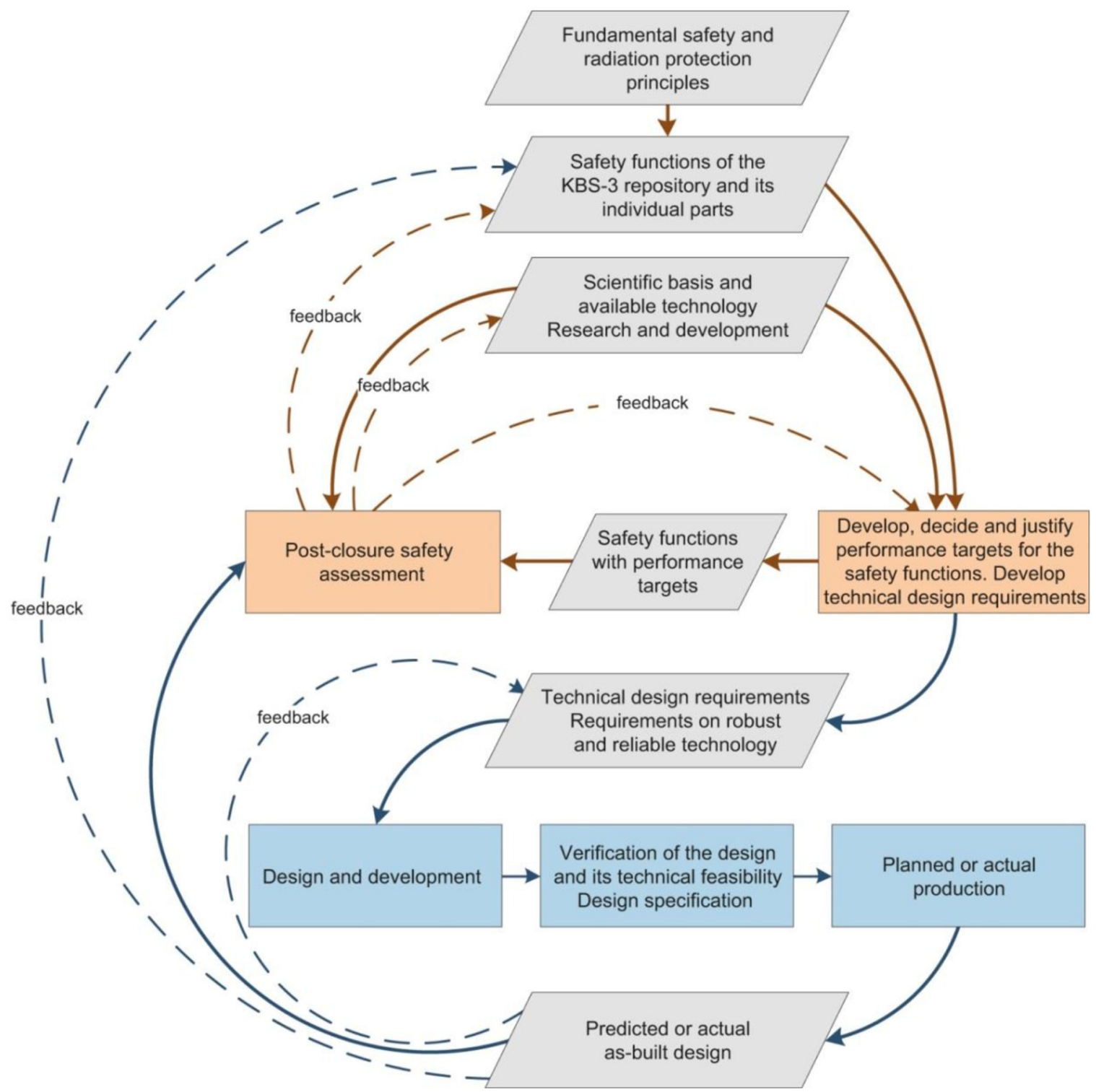

Fig. 1. The iterative process of design and safety assessment [4].

conclusion with a structured siting strategy, sufficient and long term funding, and a clear strategy for research and development.

\section{Research strategy}

\subsection{Objectives}

Research has been, and still is, one of the pillars in SKB's programme since its start in the 1970s. The objective of SKB's research programme is to secure safe management and final disposal of nuclear waste by ensuring access to the knowledge that is needed in order to assess a site, design, licence, construct and operate existing and planned facilities. This means that the research should:

- provide sufficient knowledge of post-closure safety and make sure that safety can be assessed for SKB's existing and planned facilities also in the future;
- provide sufficient information for the continued technology development and planning that is needed in order to obtain efficient and optimised solutions that at the same time provide safety both during operation and after closure of SKB's final repository.

\subsection{Iterative development of safety case, requirements and design}

SKB's programme has developed iteratively where repository designs are evaluated in safety assessments that in turn provide feedback to technology development, design and requirements, see Figure 1. At early stages, i.e. at the presentation of the KBS-3 concept [1] initial conceptual design and low resolution site data from study areas were used as inputs to safety assessments that in turn provided guidance for the future R\&D. Since the start of the siting 
programme around 1992 safety assessment also provided input to determining siting factors [2] and guidelines to the surface-based site investigations carried out during the years 2002 to 2008 [3].

At the time of the submittal of the license application SKB presented a complete safe case, SR-Site [5] constituting the basis of the application. The SSM has reviewed the safety case and while they recommend a license SSM has also identified a long list of detailed issues that need to be resolved prior to operation [6]. Provided SKB's application is accepted by the Swedish Government SKB will then update this safety case into a formal Preliminary Safety Analysis Report (PSAR) also supported by updated requirements and more detailed designs, to be submitted to SSM as a basis for obtaining a license to start underground excavation.

At later stages the PSAR will be updated to a safety analysis report (SAR) that will form the basis for the construction and operation of the repository. Each decision step for a final repository requires an assessment of postclosure safety and prior to each decision the regulator (SSM) is expected to judge whether the knowledge base concerning post-closure safety is sufficient for SSM to approve that SKB should proceed to the next step.

\subsection{In-house competence}

A key element of the research strategy has been to have sufficient in-house competence in order to maintain its ability to assimilate the knowledge that is present in the community of importance for management and final disposal of nuclear waste, and to be a skilled research client. While a repository programme will need input from a very wide range of scientific and technical disciplines the core of the in-house competence has been to maintain a coherent group of professionals with knowledge of the methodology for the assessment of post-closure safety with both wide and deep interdisciplinary insight on how the different processes that affect repository safety interact. Furthermore, by conducting its own research, SKB has ensured this maintenance of competence.

\subsection{Openness}

Another bearing principle has been that all research should be publicly available and a strive to publish results in open peer reviewed journals. In communicating with the public though media, open seminars or other event, SKB also makes sure to let the internal experts be the main spokespersons and to foster a frank and open discussion. Openness and a strive to demonstrate that there is nothing to hide, is judged as a basis for developing confidence with the public, the research community and authorities.

\subsection{International cooperation}

In building up and maintaining competence, international cooperation has been essential. This cooperation entails direct cooperation with sister organisations and using experts trained in other programmes as well as participation in the work of international organisations like the IAEA, OECD/NEA and the European Commission. These different international bodies have their different benefits.

Direct cooperation with sister organisations, like the close cooperation between SKB in Sweden and Posiva in Finland or NWMO in Canada, allows for sharing resources and ensuring that the expertise involved reaches critical mass. Both IAEA and NEA have provided platforms for interaction with peers from sister organisations and also allowed interaction with regulators from other countries. Over the years these interactions have strongly advanced the understanding on how to conduct a repository development programme and how to carry out safety assessments. While the direct funding of research projects by the European Commission has primarily not been an important means of funding, it has allowed networking on a detailed level directly with a broad range of researchers and other experts.

\section{Knowledge management tools developed}

As the programme developed from feasibility studies and basic research into site characterisation, and repository design, requirements management, workable procedures for data qualification, version control as well as internal and external peer review gained importance. These knowledge management aspects imply a major undertaking and needs to be planned.

\subsection{Data qualification}

Safety assessment and design work involves several different teams using data on e.g. fundamental processes, site characteristics and design solution and these data originate from various sources of different quality. Furthermore, different teams may need data on the same aspects and phenomena.

When SKB updated the safety assessment methodologies in the mid-1990s it was realised that it is necessary to ensure that different teams use the same data for describing the same things and that the quality of the data are assessed as well as their uncertainties [7]. Strict procedures for data and uncertainty qualification were introduced by the concept of data reports [8].

\subsection{Site descriptive modelling}

When surface-based site investigations were commenced in 2001 the concept of Site-descriptive modelling (SDM) was introduced to provide a description of the investigated sites to be used both as input to the safety assessment and to the engineering design work [9-11]. Developing an SDM entails transfer of the information from quality-assured databases produced by the site investigations to discipline-specific descriptions applicable to various subdivisions of the system made up of surfaces and volumes. The underlying field data is in its nature often point-wise, varying both spatially and temporally. Evaluation of uncertainties in values of parameters describing the material properties and 
states of the studied system and the realism in the subdivision of the studied system are central in the analyses. Included in the SDM work is control of primary data, followed by disciplinary and interdisciplinary integrated modelling providing basic geometrical descriptions and parameterisations of the bedrock and the surface system. Due to its nature and its uses, development and updating an SDM forces interaction, not only between experts from different geoscientific disciplines, but also between these experts and designing engineers and safety assessment teams.

\subsection{Peer review}

Both internal and external peer reviews are essential quality assurance tools. Starting with the site descriptive modelling works in 2001 SKB has developed and applied strict protocols for these reviews. Review plans are established defining the review criteria and the qualification of the reviewer. A review is conducted using standardized protocols where the reviewer both makes an overall assessment against the review criteria stated in the review plan and provides detailed comments. In completing the reviewed document the reviewee needs to respond to every such comment in writing. While these procedures may have been regarded as tedious in the beginning, they are now seen as essential and a safeguard against the many mistakes that otherwise would have been made.

\subsection{Requirements and quality control of production and installation}

Confidence in the post-closure safety assessment rests upon - a sufficient understanding of the Thermo, Hydro, Mechanical, Chemical and Biological processes determining the evolution of the repository system, thereby providing a necessary basis for demonstrating the repository's ability to provide adequate containment and retention, and

- a demonstration that the installed engineered barriers and the underground construction work conforms to stated technical design requirements.

For the former, the thorough process understanding achieved by decades of research is complemented by a research program tailored to the specific conditions at the chosen site. For the latter a Quality Control programme is being developed. This implies possibilities to find potential manufacturing or installation errors or other deviations in material, equipment and handling. Before and during waste emplacement, quality control provides the main source for ensuring that the as-built stage complies with stated design requirements.

The basis for the Quality Control is that there are welldefined technical design requirements against which the compliance can be checked. Formulation of design requirements is not trivial. From the Safety Assessment perspective they should be sufficient to yield a safe repository. From the designers perspective they need to be possible to implement and verify. It is easy to formulate rules that would lead to safety, but are impossible to implement and verify. Iteration and "negotiations" between safety assessment and design work is needed.

An initial set of design requirements were specified in SKB's license application for the spent fuel repository [12]. These concern what mechanical loads the barriers must be able to withstand, limitations concerning the composition and properties of the barrier materials, acceptable deviations in the dimensions of the barriers and acceptance criteria for the various underground openings.

Together with Posiva, SKB has presented revised technical design requirements for the KBS-3 barriers [4] based on the findings from the Swedish and Finnish Safety Cases on how the repository conditions affect the evolution of the safety functions, and experiences from the ongoing technology development. A Technical Design Requirement concerns the characteristics an engineered barrier or underground opening shall fulfil to be approved as a part of a KBS-3 repository. They should be derived such that if an as-built repository fulfils the technical design requirements it would help to show that safety function will be upheld in the long-term evolution. The requirements must be technically achievable and possible to verify at the latest at the time of final installation, deposition or backfilling.

\section{$4 R \& D$ challenges in coming phases}

When the programmes now enter a new phase of construction and operation new challenges will arise. While the fundamental questions regarding post closure safety should be resolved there is nevertheless a need to be prepared for and adopt new findings that might, somehow, jeopardise long term safety. Furthermore, implementation and optimisation of the new technologies may present new challenges where new research may provide essential input, although not necessarily in subject areas that traditionally have been judged important. With respect to the previous approach for producing a safety case there are some new aspects to consider.

\subsection{Safety case needs to be up to date during the entire operational time}

Although a central milestone in the level of knowledge is achieved when SKB obtains permissibility and licence to construct a new facility, the need to be able to make assessments on the safety of final repositories both during operation and after closure does not disappear. These assessments entail requirements of knowledge regarding how both the engineered barriers and the natural processes in the rock and on the ground surface interact and evolve in time. Furthermore, research and new findings regarding the long term properties will continue, both as projects driven by $\mathrm{SKB}$, projects within other implementing organisations and in the scientific community at large. There has to be a readiness to assess the safety implications of such new findings. According to the regulations, the Safety Assessment Report (SAR) should be constantly kept up-to-date. In addition, a periodic overall evaluation 

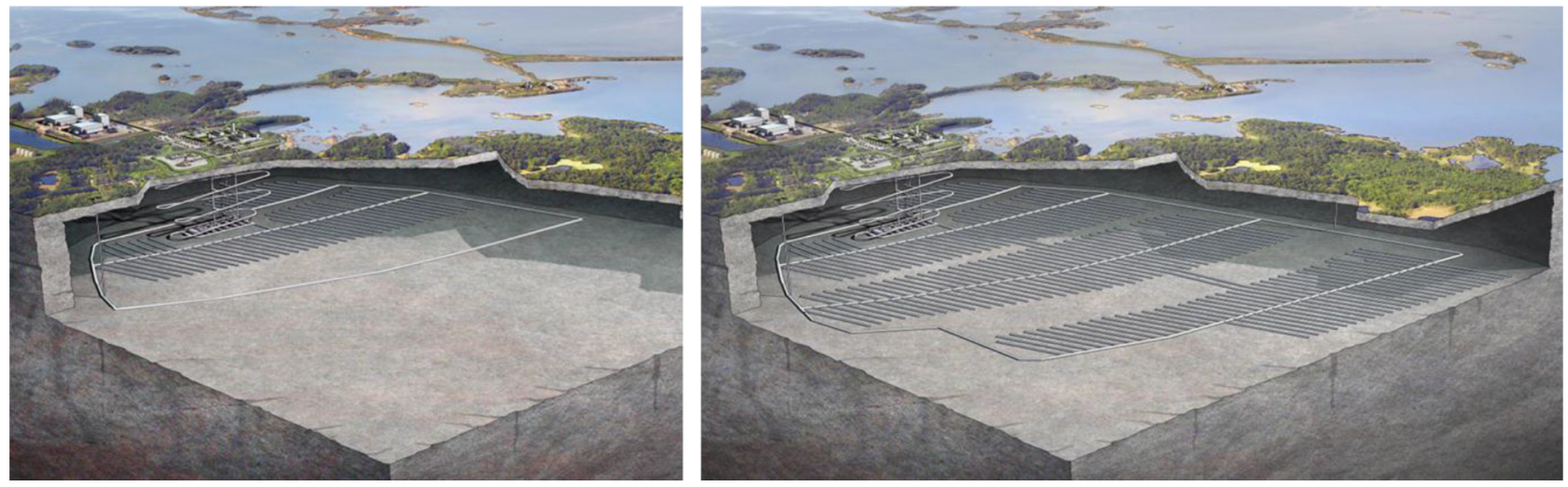

Fig. 2. During operation parts of the repository will already have been constructed, characterised and filled with deposited canisters, whereas other parts are yet to be excavated.

of the safety and radiation protection of each facility should be made every ten years according to the requirements of the Nuclear Activities Act.

\subsection{Access to detailed data from the underground and local adaption of the repository}

Once construction starts there will be new possibilities for characterization and monitoring. Underground construction implies that volumes of the host rock that are hard to characterize from the surface will be accessible to mapping and (short) borehole investigation from the excavated underground galleries [13]. Furthermore, during operation parts of the repository will already have been constructed, characterised and filled with deposited canisters, whereas other parts are yet to be excavated (Fig. 2).

The importance of detailed characterization depends on host rock and repository concept. Crystalline formations are strongly spatially variable in the sense that they are intersected by fractures and deformation zones that never will be fully characterized. Data from detailed characterization are essential for local adaptation of the location of deposition tunnels and deposition holes and ultimately to confirm site suitability since suitability would depend to what extent such local adaption is possible.

During underground construction in crystalline formations it will be possible to adapt the location of deposition tunnels and deposition holes with respect to local rock conditions. The inclusion and evaluation of such local adaption will be an important part of the safety case. Issues to consider for crystalline rock repositories include distance of the major deformation zones, location of deposition holes to ensure that these are not intersected by large fractures or fractures with potential for high water flow, selection of deposition tunnel orientation and geometry in relation to rock mechanical conditions, and to select a sufficient distance between the canisters to ensure that the bentonite temperature does not exceed the maximum allowed temperature.

Information will be continuously obtained while the repository is constructed and characterised. Pilot holes are planned to be drilled and assessed as a basis to decide whether to excavate a deposition tunnel in a particular part of the repository volume. Excavated tunnels will be mapped and characterised. Pilot holes will be drilled and characterised in potential locations for deposition holes.

While scientific issues and much of the technology to be used for this detailed characterisation is the same as was applied during surface based operation, there is a difference in scale and resolution to consider. Conditions underground, in particular recognising that characterisation will take place jointly with excavation work, imply practical limitations to characterisation such as limited time, high water pressures and confined spaces. Workers safety need also be handled and the methods applied need to be applicable in practice. Also, the speed of interpretation and modelling is essential to ensure that findings from the characterisation really can affect the decisions they are supposed to support.

\subsection{Monitoring during construction and operation}

Underground construction will also disturb the host rock. Monitoring these disturbances and comparing them with the prediction of disturbances made from the understanding based on the surface data, may provide essential information on the site properties and ongoing processes. In addition, monitoring aspects of the evolution during operation may provide further insights. While monitoring results essentially never can relate to direct safety impacts, a management structure should be in place to handle situations when monitoring results deviate from expectations.

This implies an increased need to understand also the short term changes due to the excavation. A challenge with this approach is that many disturbances caused by underground construction are of a short term transient behaviour and would often be irrelevant once the repository is finally sealed and drainage is ceased. Nevertheless, these short term issues need further attention while still maintaining the basic principle that research should focus on issues relevant to safety. 


\subsection{Relation between operational safety and post-closure safety}

Actions during operation should not only consider impacts on operational safety, but also consider how they might affect post-closure safety. While these two aspects of safety are usually not in conflict, there are a few examples of the opposite. For example, stable rock reinforcement is needed both for workers' protection and to ensure that there are no mishaps during canister emplacement, and the standard means of rock reinforcement may be detrimental to postclosure safety. Further research and development could be justified to resolve such potential conflicts.

\subsection{Proved quality control as an essential part of the safety case}

As described in Section 3.4, Technical Design Requirements (TDRs) have been updated for all barrier components. However, it is still a challenge to ensure that the TDRs are technically achievable and possible to verify at the latest at the time of final installation, deposition or backfilling. Ongoing and future technology developments focus on these aspects.

Quality control implies an assurance that the requirements made on the facilities during operation and after closure of the spent fuel repository are satisfied. Important activities in this process are to establish:

- principles for safety and quality classification,

- what is to be quality-managed and quality-controlled, and

- when quality management and control are to be performed and by whom in terms of first, second and third parties.

This needs to be established in order to qualify processes, methods, equipment and personnel for fabrication and installation, testing and inspection.

Establishing and qualifying all aspects of the quality control system for the spent nuclear fuel repository is a considerable undertaking since many of the quality needs and requirements will be unique for the repository. With respect to the canister, this implies carrying out numerical design and damage tolerance analyses. The results are used to establish dimensions and material properties (including acceptable defect frequencies and sizes) required to provide sufficient resilience to mechanical loads in the repository.

These more specific requirements are used as input to manufacturing specifications and to define the defects that need to be detected in the production and to be controlled during manufacturing, encapsulation and deposition. Among issues to consider for the bentonite components there is a need to establish practical laboratory procedures for establishing that a specific bentonite shipment confirms to the empirical (but brand-independent) TDR's. Challenges relating to underground construction and local adaptation have already been addressed in Section 4.2.

\subsection{Implementation and optimisation}

While SKB has established a technically feasible reference design and layout, detailed designs adapted to an industrialised process designed to fulfilling the specific requirements on quality, cost and efficiency need still to be developed. These updated designs should result in at least the same level of safety as the current reference design and should be implemented in the various production systems needed for the repository. These include canister production, encapsulation of spent fuel, transport, bentonite production, underground excavation and deposition activities.

Constructing and operating the repository implies that many procedures will have to operate in conjunction. While each component and each subsystem may have been tested many times new challenges will arise when all these system should operate together and in accordance with the practices of operating a nuclear facility. This means that new development needs, or even needs to revise requirements, will arise during implementation and operation.

Optimisation is another driver for additional research and development. Due to the complexity of the technical and scientific issues at hand research and development up to the license application primarily focus on developing a repository that is both safe and constructible, whereas questions regarding what is most economically optimal need to come second. Since the submittal of the license application SKB has now entered a phase of "value engineering". Value engineering is a systematic and organized approach to provide the necessary functions in a project at the lowest cost without sacrificing functionality. Issues considered include size of the underground openings, excavation methods, thermal dimensioning and deposition sequence logistics with associated need of machinery and storages. While optimisation studies appear to be very promising, they cannot be undertaken too early in the repository programme. On overall system understanding, a complete set of detailed safety functions and technical design requirements and understanding of the logistics is needed before such studies are meaningful. Otherwise there is a great risk of arriving at sub-optimal solutions.

\subsection{Knowledge management and in-house competence needed}

Research and development will need to continue also after a license to construct a repository is granted. There is also a need to apply, maintain and develop the knowledge management tools already established.

Workable procedures for information handling and QA are already developed and successfully applied but wealth of information and pressure to act quickly will increase when construction and operation starts. A structure for requirements management and quality control of production and installation is established and workable requirements are formulated, but the application during construction and operation still lies in the future. These tools will also be used by even larger groups of experts.

Due to the complexity of issues at hand implementing organisations would need to keep a core competence on post closure safety assessment including at least on overall understanding on how the repository components evolve over time. An important part in each assessment of post- 
closure safety is the evaluation of the knowledge base both with regard to processes and input data in the assessment. Safety assessments are thus fundamental for the prioritisations of the research programme. However, it may be more difficult to attract a new generation of researchers and to justify funding the R\&D when the fundamental issues are less acute.

\subsection{Role of international cooperation}

In the future, international cooperation will be even more important on developing, sharing and managing the knowledge needed. Guidelines and other recommendations issued by the international agencies will not only be important for developing programmes but would also serve as a fundamental memory in more developed programmes when the expert ones being authoring such guides now have retired or soon will retire. International cooperation is also essential for sharing competences where the national contexts is too small, especially on issues essentially only of interest to the nuclear waste community. Participation in international work may also be an inspiration and reason to carry on for internal staff, as well as researches at universities, to consider the work sufficiently interesting.

\section{Conclusions}

SKB is closing the back end of the fuel cycle, but research and development would need to continue, although with a new focus. There is also a need to apply, maintain and develop the knowledge management tools already established. In the future, international cooperation will be even more important on developing, sharing and managing the knowledge needed.

\section{References}

1. KBS 3, Final storage of spent nuclear fuel, Swedish Nuclear Fuel Supply Co/Division KBS (SKBF/KBS), available at www.skb.se, 1983
2. J. Andersson, A. Ström, C. Svemar, K.-E. Almén, L.O. Ericsson, What requirements does the KBS-3 repository make on the host rock? Geoscientific suitability indicators and criteria for siting and site evaluation, SKB TR-00-12, Svensk Kärnbränslehantering AB, 2000

3. Geoscientific programme for investigation and evaluation of sites for the deep repository, SKB TR-00-20, Svensk Kärnbränslehantering AB, 2000

4. Safety functions, performance targets and technical design requirements for a KBS-3V repository, Posiva SKB Report 01, Posiva Oy, Svensk Kärnbränslehantering AB, 2017

5. Long-term safety for the final repository for spent nuclear fuel at Forsmark, Main report of the SR-Site project, SKB TR-1101, Svensk Kärnbränslehantering AB, 2011

6. Strålsäkerhet efter slutförvarets förslutning (in Swedish: Radiation safety after closure of the final repository for spent nuclear fuel), Swedish Radiation Safety Authority 2018, 07, 2018

7. J. Andersson, Data and data uncertainties, Compilation of data and data uncertainties for radionuclide transport calculations, SKB TR-99-09, Svensk Kärnbränslehantering AB, 1999

8. Data report for the safety assessment SR-Site, SKB TR-1052, Svensk Kärnbränslehantering AB, 2010

9. Site description of Forsmark at completion of the site investigation phase, SDM-Site Forsmark SKB TR-08-05, Svensk Kärnbränslehantering, 2008

10. Olkiluoto Site Description, POSIVA Report 2011-2012, Posiva Oy, Finland 2011

11. J. Andersson, K. Skagius, A. Winberg, T. Lindborg, A. Ström, Site-descriptive modelling for a final repository for spent nuclear fuel in Sweden, Environ. Earth Sci. 69, 1045 (2013)

12. Design premises for a KBS-3V repository based on the results from the safety assessment SR-Can and some subsequent analyses, SKB TR-09-22, Svensk Kärnbränslehantering AB, 2009

13. Detailed site investigation programme in conjunction with construction and operation of a repository for spent nuclear fuel, SKB R-17-16, Svensk Kärnbränslehantering AB, 2017

Cite this article as: Johan Andersson, Science underpinning the safety case of deep geological repositories - challenges in the past and in the future and how to maintain knowledge and competence during operation, EPJ Nuclear Sci. Technol. 6, 24 (2020) 